\section{The road ahead for brain-circuit reconstruction}

As someone who has spent the past 25 years charting brain circuits, I am baffled by the view expressed in your Technology Feature that "sadly, ... pretty much" nothing has happened in my field since the early $1980 \mathrm{~s}$ (Nature 461, 1149-1152; 2009).

Unlike structural descriptions of the Universe, fossil bones or molecules, neural structure has not been a vote-winner among high-profile journals. However, neurocircuiteers have not been waiting patiently in their backwater for a quarter of a century for the arrival of new molecular, genetic and imaging techniques. They have been describing circuits through a variety of clever physiological and anatomical experiments, coupled with hard theory and analysis.

The new techniques offer no improvement in resolution over those that have been available for more than 50 years. Electrophysiology and light and electron microscopy are still the gold standards in space, time and reach for studying any region of any brain.

The new thing these structural techniques promise is volume. This is great, because it means that the wiring diagrams of small brains such as Drosophila's may become available in a decade or so.

One elephant remains in the room. How do we use the circuit reconstructions (involving exabytes of data) that these high-throughput techniques deliver?

Loading any circuit into the biggest super-simulator available and switching on tells us nothing useful. Like a motorcar without wheels being started up by a Martian, exciting noises may come from the exhaust but it isn't going to take us anywhere. It is coupling these powerful techniques to predictive models of neural circuits that will really allow us to go places.

Kevan A. C. Martin Institute of Neuroinformatics, UZH/ETH, Winterthurerstrasse 190, 8057 Zurich, Switzerland e-mail:kevan@ini.phys.ethz.ch

\section{Darwin respected by his religious contemporaries}

The Church in England did not generally react so "badly" to Darwin's ideas as readers of your Editorial may be led to believe (Nature 461, 1173-1174; 2009).

Reverend Charles Kingsley, Regius Professor at the University of Cambridge, UK, wrote in 1863

"God's greatness, goodness and perpetual care I never understood as I have since I became a convert to Mr Darwin's views." The Bishop of Carlisle, Harvey Goodwin, proclaimed after Darwin's funeral in Westminster Abbey "It would have been unfortunate if anything had occurred to give weight and currency to the foolish notion which some have diligently propagated, but for which Mr Darwin was not responsible, that there is a necessary conflict between a knowledge of Nature and a belief in God." In 1884 Frederick Temple, Bishop of Exeter and future Archbishop of Canterbury, wrote "The doctrine of Evolution restores to the science of Nature the unity which we should expect in the creation of God." Aubrey Moore, a leading theologian at the University of Oxford, welcomed Darwinism "as a friend in the disguise of a foe" because it struck at the heart of nineteenth-century deism.

Ironically, in view of later developments, even some of the authors of Fundamentals (a series of Christian booklets published in the United States between 1910 and 1915) were happy to see evolution as the method that God used in his work of creation.

The assumption that there must be conflict between evolution and religion was (and is) the result of the distorting "cultural lenses" that you mention. Modern 'creationism' was born only in the twentieth century, largely through the efforts of the Canadian adventist George McCready Price. There has probably been less conflict in England than in most other countries.

None of this is to claim that all religious people view evolution in a positive light, nor that all evolutionists are objective about religion. But we need to remain aware of our cultural lenses.

R. J. Berry Department of Biology, University College London, London WC1E 6BT, UK e-mail: rjberry@ucl.ac.uk

\section{Why some relatives object to organ donation}

You question in an Editorial the determination of death for organtransplant purposes in the United States, where explantation can go ahead once all functions of the entire brain have irreversibly ceased (Nature 461, 570; 2009). Nothing so rigorous is demanded in the United Kingdom.

For successful transplantation, major organs such as the heart, lungs, bowel and liver must be alive. For some 30 years, UK practice has required only bedside tests purporting to show an irreversible loss of ability to breathe and the irreversible cessation of some brainstem functions. Higher parts of the brain may continue to function. As a consultant anaesthetist (now retired), it greatly concerns me that the donor will need some form of paralysis and anaesthesia to control the responses to explantation surgery.

The UK technical definition of death for transplantation purposes is not explained on donor cards or on the donor register, so those who sign up may have a quite different concept of "my death". This may explain the $40-50 \%$ refusal rate among relatives when they observe the condition of someone declared dead but still showing signs associated with life.

David J. Hill Eltisley, Huntingdon, Cambridgeshire PE19 6TG, UK e-mail:david.hill01@tiscali.co.uk

Readers are welcome to join this debate at Nature Network, go.nature.com/WjUiku.

\section{Brazil's system stops its natural wealth helping science}

The pessimism expressed in your Naturejobs feature about the prospects for life sciences in Brazil is justified (Nature 461, 1308-1309; 2009). Unfortunately, the country's science enterprise depends as much on its societal values as on its booming economy and wealth of natural resources.

Brazil's prevailing political and cultural outlook means that its economic growth has not proportionately reduced its chronic poverty and income inequalities. Nor has this growth promoted modernization of its political or financial systems - education, science and technology included.

Poor management of Brazil's abundant natural resources means that, although these account for some $68 \%$ of its positive trade balance, the country is left with less than $1 \%$ of the money created from its mineral exports. For example, Brazilian iron exports alone totalled US $\$ 16$ billion last year; however, mining royalties amounted to only $\$ 462$ million. And with gold royalties at just $1 \%$, Brazil has the world's lowest taxation on gold.

Some sectors are campaigning for new legislation to remedy this situation. A separate strategy will be needed to direct any additional government money towards improving Brazilian science.

Sergio U. Dani Excegen Genetica SA, Acangaú Valley, CxP 123, 38600-000 Paracatu MG, Brazil e-mail:srgdani@gmail.com 